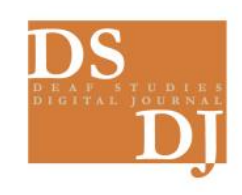

\title{
A Sound Disappearance
}

\section{Cindy Officer}

Gallaudet University, www.gallaudet.edu

cindy.officer@gallaudet.edu

Key Words: audism, phonocentrism, oppression, focus group, deaf voice

\begin{abstract}
A deaf parent of a deaf preteen describes how audism manifested through phonocentric processes that transpired during a 90-minute focus group hosted by a public school system. The intent of the focus group was to collect input on the redesign of the school system's deaf and hard of hearing programs. While the number of deaf participants exceeded the number of hearing participants, critical input from deaf participants was diminished, misconstrued, and overlooked in favor of the input from hearing participants.
\end{abstract}

\section{Translation}

\section{Chapter 1 High Ranking Fairfax County Public Schools}

Fairfax County Public Schools (FCPS) reports that 95\% of its high school graduates attend postsecondary programs. FCPS enrolls more students than any county in the state of Virginia and has the 12th largest student enrollment in the United States. 1 FCPS has also earned a favorable reputation for its mainstream programs for the deaf. In Fairfax County there are three designated elementary schools for deaf and hard of hearing children, each with a different communication focus: One school provides an oral communication program, another provides a cued speech program, and the last provides a sign communication program.

The elementary school that houses the sign communication program is well known for implementing multicultural-multilingual research-based practices. Many students of international origin attend this school. This school provides a wide selection of interpreters and translators for events and public documents, meaning users of different languages have access to school-related information. Deaf and hard of hearing parents and students using American Sign Language are no different. ASL Interpreters are used for every event. The perception of deaf and hard of hearing students by their peers and teachers seems egalitarian. As a family, we were thrilled with the school's positive perception of deaf and hard of hearing children. We moved inside the school boundary so our younger two sons could attend.

I learned this past summer that FCPS formed a steering committee charged with redesigning programs for deaf and hard of hearing elementary students. The biggest suggestion posed by the committee is to merge the three separate programs - oral, cued and sign - and establish the deaf and hard of hearing program at one site. 


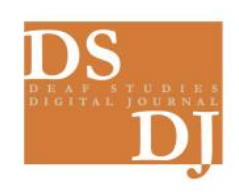

In forethought, the steering committee solicited feedback from parents and community members through a 90-minute focus group to collect input on how to redesign programs for deaf and hard of hearing children.

\section{Chapter 2 The Focus Group}

The night of the focus group, I entered a school gym to find many deaf, hard of hearing and hearing people in attendance. A man stood up and began with an announcement that the decision to merge the three programs had been fairly firm due to fiscal constraints and increasing number of deaf and hard of hearing children with additional disabilities. He instructed the audience to split into four groups. Each of the four groups went to an assigned classroom.

My classroom had U-shaped row with 13 seats. Two facilitators greeted us and explained that one would transcribe our comments and one would lead the discussion. Two ASL interpreters sat in the front of the room with the facilitators. The first four seats were occupied by hearing participants. The fifth seat was occupied by a deaf participant. The sixth seat was occupied by a hearing participant. Seats seven through thirteen were occupied by deaf participants with me sitting in the last seat.

The leading facilitator explained that there were two questions. With each question everyone would have a chance to supply suggestions, round-robin style. The first question stated, "What is important to consider in deaf and hard of hearing programs?" The second question asked, "What specific recommendations do you have for the redesign related to instruction, social interaction, resources, and services for the deaf and hard of hearing students in the program?"

The discussion began seamlessly with the first four hearing participants voicing their comments. As information flowed, the transcriber wrote the speakers' comments on a flipchart. When it came to the first deaf speaker, the process lurched and stalled. Her comments were not recorded. The next person, a hearing mother of a deaf child, spoke and the recursive process of speaking-transcribing picked up again. After her, there were five more deaf people trying to articulate their suggestions but very little information was actually being recorded on the flipchart. Comments dictated by deaf participants that were written on the flipchart were vague and blithe, contrary to the speaker's intent. Most was not being recorded. I tried to figure out where communication gaps were happening. The two interpreters had teamed up and were working hard to convey what was being signed. Quickly I began writing what other deaf people were saying knowing I would be last to sharing comments. When my turn came, I used my voice to vocalize comments. I know I sign but felt urgency in getting other perspectives fairly and accurately recorded. As I spoke the transcriber wrote but she did not accurately record what I was trying to say. I made both facilitators backtrack and record verbatim comments that were lost through sign. Their irritation became obvious. Through the whole process, my innards tightened and nausea swept over me. It sickened me that I had to take the power of articulation from other deaf participants and regurgitate their comments through speech.

Some lost comments included:

- Yes, merge the three programs for deaf and hard of hearing children but make sure that its leaders acknowledge the hegemony of oralism and implement practices that prevent it.

- Deaf culture is real and an important part of education. Leaders need to make fiscal decisions that do not oppress the cultural group, like reducing sign language interpreting services. 
- Encourage a positive worldview in deaf and hard of hearing children as multilinguals and freely expose them to all modalities including oralism, cued speech and ASL.

- Deaf and hard of hearing people need to be hired by FCPS to work with the deaf and hard of hearing children and to serve as positive role models.

As I progressed through the list, the facilitator grew increasingly frustrated with me. With a strong scowl on her face, she suggested that I was off-topic and pressing time constraints.

When I concluded with the final comments, the next round to address the second question began. The first four participants clamored with voices overlapping and comments being tossed around. Other hearing people began voting on one another's comments. As the voting escalated, the turn-taking stopped. Deaf participants tried to interject but the two interpreters could not voice for eight. Soon deaf participants fell silent, as if turned into ghosts. Again, with voice, I interrupted, "Is this a vote? Why the tallymarks?" The lead facilitator said, "This is not a vote," but the tallymarks on the flipchart suggested otherwise. The commotion ended at that point and turn-taking resumed.

But most of the deaf participants, one by one, declined his or her turn to comment. When it came to my turn, I once again spoke and signed with knots in my stomach. Final comments were diluted, hampered by the sense of futility. We were rendered ghosts.

\section{Chapter 3 Questions on Phonocentrism}

Now, looking back at the ordeal, I'm struck by this tiny example in a long history of struggle in deaf education. Looking at this nameless obstruction, I wonder how to identify it. Could it be called, "phonocentrism" - which means spoken voice is superior to sign? Consider this: Spoken English and spoken Spanish could produce an even and egalitarian exchange of information, even if the speakers do not the other's language - but signed languages are perceived as lower than spoken languages. The experience with the FCPS focus group exemplifies phonocentrism. I wonder how often this happens around the United States. I wonder how often this happens worldwide.

Given the strife-ridden history of deaf and hard of hearing education, it may be time to view these conflicts through a new lens: Phonocentrism. We need to ask ourselves: 1 . How do we identify phonocentrism? 2. How does phonocentrism impact the future of our deaf and hard of hearing children 3. How do we educate those in power to reduce phonocentric attitudes? 


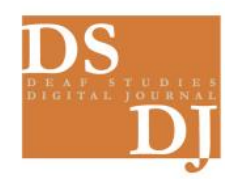

है।

\section{References:}

Fairfax County Public Schools. (2010). Statistics. Retrieved October 14, 2010 from www.fcps.edu/ statis.htm\#fairfaxcounty.

Phonocentrism was initially a word identified by Jolanta Lapiak in Handspeak. Retrieved September 23, 2010 from www.handspeak.com/byte/p/index.php?byte=phonocentrism. 